Check for updates

Cite this: RSC Adv., 2019, 9, 33558

Received 17th September 2019 Accepted 14th October 2019

DOI: $10.1039 / c 9 r a 07499 f$

rsc.li/rsc-advances

\title{
Preparation of an $\mathrm{Fe}_{2} \mathrm{Ni}$ MOF on nickel foam as an efficient and stable electrocatalyst for the oxygen evolution reaction $\uparrow$
}

\author{
Xintong Ling,,$^{\text {ac }}$ Feng Du, ț ${ }^{\text {ac }}$ Yintong Zhang, ${ }^{\text {ac }}$ Yan Shen, ${ }^{\text {ce }}$ Tao Li, (DD *b \\ Ahmed Alsaedi, ${ }^{\text {Tasawar Hayat }}{ }^{\text {fg }}$ Yong Zhou (D) *acd and Zhigang Zou ${ }^{\text {acd }}$
}

\begin{abstract}
Metal-organic frameworks (MOFs) as versatile templates for preparing transition metal compounds has received wide attention. Benefiting from their diversified spatial structure and controllable chemical constituents, they have become a research hotspot in the field of electrocatalytic water splitting. Herein, $\mathrm{Fe}_{2} \mathrm{Ni}-\mathrm{MIL}-88 \mathrm{~B}$ MOF on nickel foam ( $\mathrm{Fe}_{2} \mathrm{Ni} \mathrm{MOF} / \mathrm{NF}$ ) has been prepared through a one-pot method growth process. Compared with $\mathrm{Fe}$ MOF/NF and $\mathrm{Ni}$ MOF/NF, the interaction between $\mathrm{Fe}^{3+}$ and $\mathrm{Ni}^{2+}$ in $\mathrm{Fe}_{2} \mathrm{Ni} \mathrm{MOF} / \mathrm{NF}$ accelerates the electron transfer through the oxygen of the ligand, leading to increased $3 d$ orbital electron density of $\mathrm{Ni}$, which enhances the activity of the oxygen evolution reaction (OER) in alkaline solution. $\mathrm{Fe}_{2} \mathrm{Ni}$ MOF/NF provides a current density of $10 \mathrm{~mA} \mathrm{~cm}{ }^{-2}$ at a low overpotential of $222 \mathrm{mV}$, and its Tafel slope is also very small, reaching $42.39 \mathrm{mV} \mathrm{dec}^{-1}$. The success of the present $\mathrm{Fe}_{2} \mathrm{Ni}$ $\mathrm{MOF} / \mathrm{NF}$ catalyst is attributed to the abundant active centers, the bimetallic clusters $\mathrm{Fe}_{2} \mathrm{Ni}-\mathrm{MIL}-88 \mathrm{~B}$, the positive coupling effect between $\mathrm{Ni}$ and Fe metal ions in the MOF, and synergistic effect between the MOF and NF. Besides, $\mathrm{Fe}_{2} \mathrm{Ni}$ MOF/NF possesses excellent stability over $50 \mathrm{~h}$ of continuous operation, providing feasibility for commercial use.
\end{abstract}

\section{Introduction}

In the last few years, with the rapid development of industrial production and the increasing population, the demand for fossil energy has increased. ${ }^{\mathbf{1}}$ However, environmental pollution and global warming have driven the necessity of searching for clean energy. It is imperative to exploit and utilize renewable energy. ${ }^{2-4}$ Electrocatalytic water splitting is a research director with great potential at present, which includes two halfreactions: the oxygen evolution reaction (OER) and the hydrogen evolution reaction (HER). Due to involving multiple reaction steps from water to $\mathrm{O}_{2}$, the OER process has been considered as the bottleneck. ${ }^{5}$ Some noble-metal-based materials, such as $\mathrm{RuO}_{2}$ and $\mathrm{IrO}_{2}$, have relatively high electrocatalytic activity for the OER. However, their scarcity limits their largescale application. ${ }^{6,7}$ The search for OER electrocatalysts with

${ }^{a}$ School of Physics, National Laboratory of Solid State Microstructures, Nanjing University, Nanjing, Jiangsu 210093, P. R. China. E-mail: zhouyong1999@nju. edu.cn

${ }^{b}$ Engineering Technology Research Center of Henan Province for Solar Catalysis, School of Chemistry and Pharmaceutical Engineering, Nanyang Normal University, Nanyang, Henan 473061, P. R. China.E-mail: ltao84@163.com 'Jiangsu Key Laboratory for Nano Technology, Nanjing University, Nanjing, Jiangsu 210093, P. R. China

${ }^{d}$ Kunshan Innovation Institute of Nanjing University, Kunshan, Jiangsu 215347, P. R. China high efficiency and low cost of nonprecious metal materials has become an important task.

Transition metal compounds have been widely reported as effective OER electrocatalytic materials, including oxides, hydroxides, sulfides, nitrides and phosphides. ${ }^{8-14}$ Meanwhile, it is necessary to design rational engineering, in which the active sites should be fully exposed. Here, as a new nano-porous material with special structure, metal-organic framework (MOF) has some unique properties, including tunable pore sizes, large specific surface area, and perfect nanostructures. And it has obtained exciting application value in energy storage, catalysis, gas storage, etc. ${ }^{15-21}$ Generally, due to the low conductivity and stability of single metal MOF, it is rarely used as a direct electrocatalyst. ${ }^{22}$ The mixed metal MOF material was relatively stable and efficient. Besides, the bimetallic nickel-iron composites were identified as one of the most promising electrocatalysts for the OER, in which the interaction between 
metals could promote the process of electrocatalytic reaction. Therefore, nickel-iron MOF material would show great potential for development in water splitting. . $^{\mathbf{2 3} 24}$

In our work, Fe and Ni-based MOF on nickel foam (NF) had been prepared by a one-pot method, which was known as $\mathrm{Fe}_{2} \mathrm{Ni}$ MIL-88B MOF ( $\left.\mathrm{Fe}_{2} \mathrm{Ni} \mathrm{MOF}\right)$. This MOF exhibited a loose nanosheet structure. And the bimetallic system accelerated the electron transfer between $\mathrm{Fe}^{3+}$ and $\mathrm{Ni}^{2+}$ through the oxygen of the ligand to increase $3 \mathrm{~d}$ orbital electron density of $\mathrm{Ni}^{25,26} \mathrm{Fe}_{2} \mathrm{Ni}$ MOF is different from other NiFe MOF. Firstly, this MOF was a composite of Fe and Ni, not a mixture of Fe MOF and Ni MOF, so that electron transfer can be carried out between the Fe and $\mathrm{Ni}$ elements to improve OER activity. Secondly, $\mathrm{Fe}_{2} \mathrm{Ni} \mathrm{MOF}$ 's ligand was different from other Ni Fe MOF, so it has a special morphology that could increase the active site. Finally, the success of the present $\mathrm{Fe}_{2} \mathrm{Ni} \mathrm{MOF} / \mathrm{NF}$ catalyst is attributed to the synergistic effect between the MOF and NF. Specifically, compared with the monometallic MOF materials (Fe MOF/NF and $\mathrm{Ni} \mathrm{MOF} / \mathrm{NF}$ ), $\mathrm{Fe}_{2} \mathrm{Ni} \mathrm{MOF} / \mathrm{NF}$ had better performance in OER. It exhibited a low overpotential of $222 \mathrm{mV}$ at a current density of $10 \mathrm{~mA} \mathrm{~cm}^{-2}$, and a small Tafel slope of $42.39 \mathrm{mV}$ $\mathrm{dec}^{-1}$. More importantly, $\mathrm{Fe}_{2} \mathrm{Ni} \mathrm{MOF} / \mathrm{NF}$ possessed excellent electrochemical durability of 50 hours for potential applications in the future.

\section{Experimental}

\subsection{Preparation of $\mathrm{Fe}_{2} \mathrm{Ni} \mathrm{MOF} / \mathrm{NF}, \mathrm{Fe} \mathrm{MOF} / \mathrm{NF}$, and Ni MOF/ NF}

Generally, a small piece of nickel foam $(\mathrm{NF})(1 \times 6 \mathrm{~cm})$ ultrasonically was washed in acetone, water, hydrochloric acid and ethanol to remove organic residues on the surface before use. The $\mathrm{Fe}_{2} \mathrm{Ni} \mathrm{MOF} / \mathrm{NF}$ was prepared by a one-pot method. First, $0.7 \mathrm{mmol} \mathrm{Fe}(\mathrm{NO})_{3} \cdot 9 \mathrm{H}_{2} \mathrm{O}(0.2828 \mathrm{~g})$ and $0.3 \mathrm{mmol} \mathrm{NiCl}_{2} \cdot 6 \mathrm{H}_{2} \mathrm{O}$ $(0.0713 \mathrm{~g})$ were dissolved in $N, N$-dimethyl formamide (DMF). Then $1 \mathrm{mmol}$ terephthalic acid (TPA), $2.5 \mathrm{~mL}$ deionized water and $2.5 \mathrm{~mL}$ ethanol was slowly added to the above solution with continuous stirring. After 30 minutes, the mixture was transferred to a $50 \mathrm{~mL}$ Teflon-lined stainless-steel autoclave. Then the processed NF was immersed in the mixture. The autoclave was then placed in an oven at $125^{\circ} \mathrm{C}$ for 12 hours. After natural cooling, $\mathrm{Fe}_{2} \mathrm{Ni} \mathrm{MOF} / \mathrm{NF}$ was taken out and washed several times with deionized water and ethanol, and dried at $60{ }^{\circ} \mathrm{C}$ for 2 hours. Fe MOF/NF and Ni MOF/NF could be synthesized in the same way without adding $\mathrm{NiCl}_{2} \cdot 6 \mathrm{H}_{2} \mathrm{O}$ or $\mathrm{Fe}(\mathrm{NO})_{3} \cdot 9 \mathrm{H}_{2} \mathrm{O}$, respectively.

\subsection{Material characterization}

The crystalline phase of the sample was obtained on a Rigaku Ultima III diffractometer using X-ray diffraction (XRD) with $\mathrm{CuK} \alpha$ radiation $(\lambda=0.154178 \mathrm{~nm})$. The scan range was $5-40^{\circ}$ and the scan speed was 2.4 degrees per minute. The morphology and energy-dispersion X-ray spectroscopy (EDX) of the various samples was observed with scanning electron microscopy (SEM) and performed with an S-3400 N II instrument. X-ray photoelectron spectroscopy (XPS, PHI 5000 Versa
Probe UlVAC-PHI, Japan) was used to obtain the XPS data of the materials, with reference to C 1s (binding energy of $284.8 \mathrm{eV}$ ).

\subsection{Electrochemical measurements}

The electrochemical activity of all samples was tested using a 1.0 $\mathrm{M} \mathrm{KOH}$ solution in a typical three-electrode configuration using a CHI660E electrochemical workstation analyzer. The standard $\mathrm{Ag} / \mathrm{AgCl}$ electrode was used as the reference electrode while the carbon rod and the synthetic sample was used as the counter electrode and the working electrode, respectively. The linear sweep voltammograms (LSV) for OER was carried out in 1.0 $\mathrm{M} \mathrm{KOH}$ at a scan rate of $2 \mathrm{mV} \mathrm{s}^{-1}$. In order to eliminate the interference of the solution resistance, all measured LSV were iR-corrected. A constant current of $10 \mathrm{~mA} \mathrm{~cm}{ }^{-2}$ was used for measuring long-term electrochemical stability. The recording frequency range for electrochemical impedance spectroscopy (EIS) measurement was $100 \mathrm{kHz}$ to $0.01 \mathrm{~Hz}$. All of the potentials herein were converted to the corresponding potentials relative to RHE using the following equation: $E_{\mathrm{RHE}}=E_{\mathrm{Ag} / \mathrm{AgCl}}+0.197+$ $0.0591 \times \mathrm{pH}$, where $E_{\mathrm{RHE}}$ was the potential measured relative to the potential of $\mathrm{RHE}$ and the $E_{\mathrm{Ag} / \mathrm{AgCl}}$ was the potential measured by the $\mathrm{Ag} / \mathrm{AgCl}(3 \mathrm{M} \mathrm{KCl})$ reference electrode, respectively.

\section{Results and discussion}

In this report, the method for preparing $\mathrm{Fe}_{2} \mathrm{Ni} \mathrm{MOF}$ grown on NF was illustrated in Scheme 1. During the solvothermal reaction, $\mathrm{Fe}_{2} \mathrm{Ni}$ MOF were formed in an orderly way on the surface of the NF (Fig. S1 $\dagger$ ). The composition of the three products was studied by X-ray diffraction (XRD) pattern by using the powder scraped from the corresponding substrates as shown in Fig. 1. The XRD pattern of Ni MOF has two sharp peaks at $9.3^{\circ}$ and $18.5^{\circ}$, which match well with the (100) and (200) planes of $\left[\mathrm{Ni}_{3}(\mathrm{OH})_{2}\left(\mathrm{C}_{8} \mathrm{H}_{4} \mathrm{O}_{2}\right)_{2}\left(\mathrm{H}_{2} \mathrm{O}\right)_{4}\right]$ (CCDC no. 638866 $\left.\dagger\right) .{ }^{27}$ Fe MOF was confirmed with the diffraction pattern of $\mathrm{Fe}_{3}$-MIL-88B. ${ }^{28}$ In patterns of $\mathrm{Fe}_{2} \mathrm{Ni}$ MOF samples, the main diffraction peaks that appeared around $2 \theta$ of $7.3^{\circ}, 8.9^{\circ}, 9.3^{\circ}, 9.9^{\circ}, 16.8^{\circ}, 17.7^{\circ}$, and $21.9^{\circ}$ are similar to those previously reported for MIL-88B. ${ }^{28}$ The MIL-88B structure was established as the prominent and

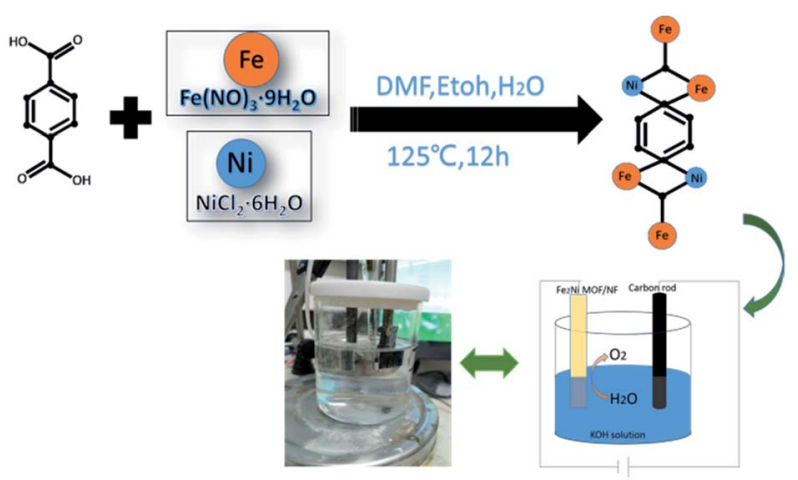

Scheme $1 \mathrm{Fe}_{2} \mathrm{Ni}-\mathrm{MIL}-88 \mathrm{~B}$ MOF on nickel foam ( $\mathrm{Fe}_{2} \mathrm{Ni} \mathrm{MOF} / \mathrm{NF}$ ) has been prepared through a one-pot method growth process. 


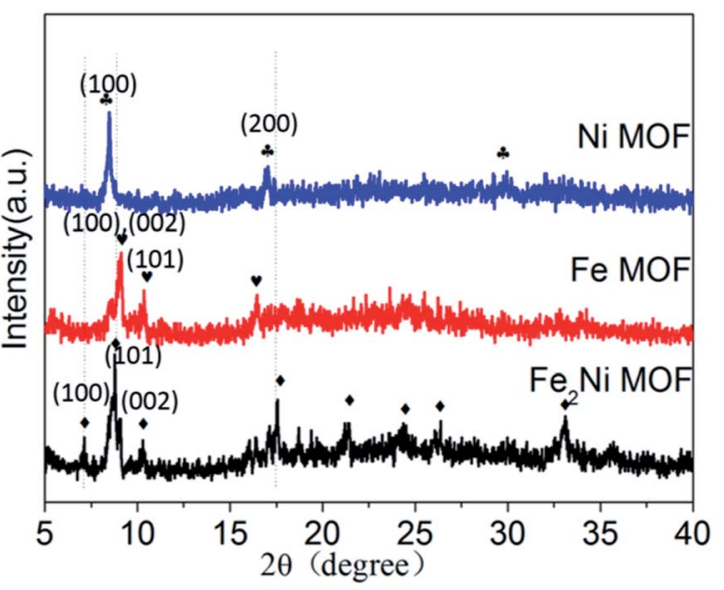

Fig. 1 XRD patterns of $\mathrm{Fe}_{2} \mathrm{Ni} M O F / N F$, Fe MOF/NF, and Ni MOF/NF.

characteristic planes (100), (101) and (002) appeared. ${ }^{29}$ Additionally, we can see that the Bragg peaks of the XRD patterns show displacements. Férey et al. have reported that the swelling up of the MIL-88B structure causes the splitting and shifting to a low $2 \theta$ of the planes (100) and (101). ${ }^{30}$ With the presence of $\mathrm{Ni}^{2+}$ in the reaction solution, MIL-88B crystals were made up and the crystallinity of the material increased.
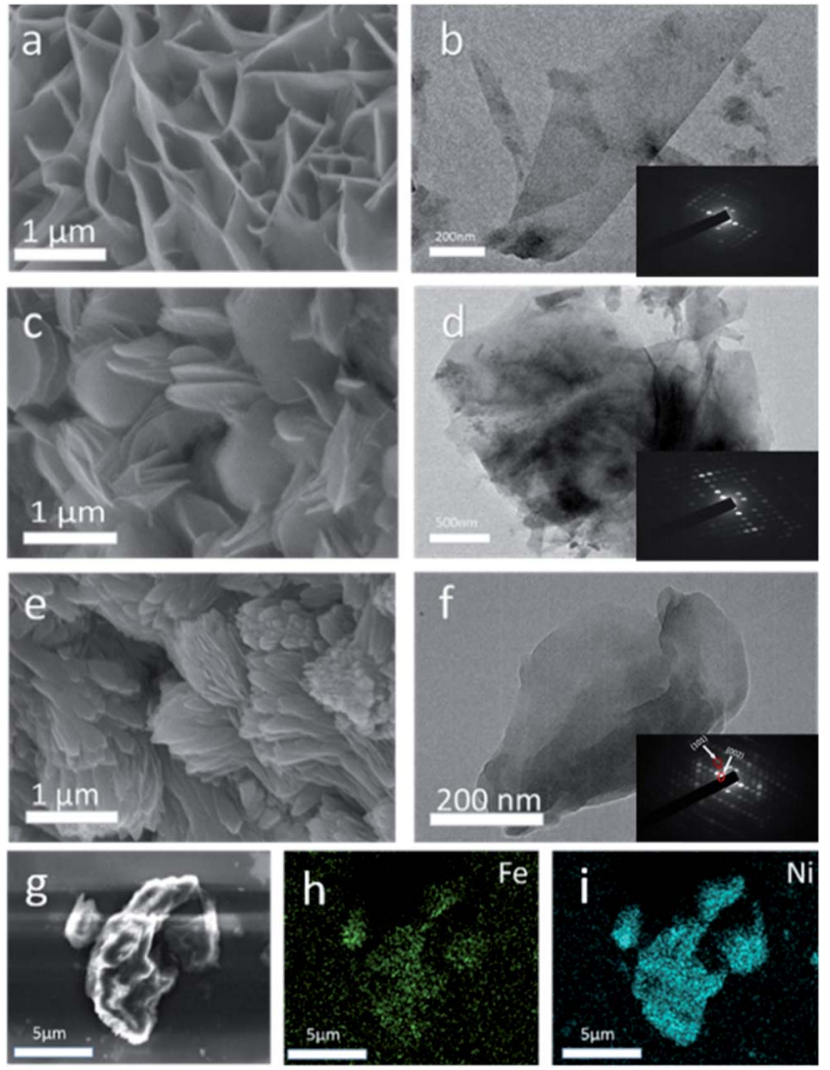

Fig. 2 SEM images of (a) Ni MOF/NF, (c) Fe MOF/NF and (e) $\mathrm{Fe}_{2} \mathrm{Ni}$ $\mathrm{MOF} / \mathrm{NF}$, (b, d, and f) TEM images of $\mathrm{Ni} M O F / N F, ~ F e ~ M O F / N F$, and $\mathrm{Fe}_{2} \mathrm{Ni}$ MOF/NF. (Inset of $b, d$, and f): SAED pattern of Ni MOF/NF, Fe MOF/NF, and $\mathrm{Fe}_{2} \mathrm{Ni} \mathrm{MOF} / \mathrm{NF}$. (g) SEM image of the $\mathrm{Fe}_{2} \mathrm{Ni}$ MOF/NF. EDS mapping images of (h) $\mathrm{Fe}$ and (i) $\mathrm{Ni}$ for the $\mathrm{Fe}_{2} \mathrm{Ni} \mathrm{MOF}$.
SEM images showed the morphology of Ni MOF/NF, Fe MOF/ $\mathrm{NF}$ and $\mathrm{Fe}_{2} \mathrm{Ni} \mathrm{MOF} / \mathrm{NF}$ (Fig. 2a, c, and e), respectively. As shown in Fig. 2a, Ni MOF showed the structure of nanosheet arrays and the uniform coverage over the backbone surface of the NF (Fig. S2a and $b \dagger$ ). ${ }^{31}$ While Fe MOF/NF had the typical shell-like morphology. $\mathrm{Fe}_{2} \mathrm{Ni} \mathrm{MOF} / \mathrm{NF}$ exhibited a spindle shape, which different from Ni MOF and Fe MOF. So they have different compositions, crystal structure, and the pore structure, their morphology is completely different. Fig. S3 $\uparrow$ reveals that the $\mathrm{Fe}_{2} \mathrm{Ni} \mathrm{MOF} / \mathrm{NF}$ still maintains its spindle shape after the stability test. And the samples with different ratios of $\mathrm{Ni}$ to $\mathrm{Fe}$ (Fig. S3a and $\mathrm{b} \dagger$ ), from SEM images of $\mathrm{Fe}: \mathrm{Ni}=3: 7$ and $\mathrm{Fe}: \mathrm{Ni}$ $=5: 5$, we can find that they have sheet structure similar to $\mathrm{Ni}$ MOF, which imply they have a mixture of Ni MOF and $\mathrm{Fe}_{2} \mathrm{Ni}$ MOF. SEM image of $\mathrm{Fe}_{2} \mathrm{Ni}$ MOF (Fig. 2g) and high-quality EDS images into Fig. $2 \mathrm{~h}$ and i clearly shows the presence of $\mathrm{Fe}$ and $\mathrm{Ni}$ elements in the $\mathrm{Fe}_{2} \mathrm{Ni}$ MOF. The TEM images of $\mathrm{Fe}_{2} \mathrm{Ni} \mathrm{MOF} / \mathrm{NF}$, $\mathrm{Ni} \mathrm{MOF}$, and Fe MOF confirmed the respective morphological characteristics. And the selected area electron diffraction (SAED) of the three insets (Fig. 2b, d, and f) indicated the singlecrystal of the samples. Additionally, from SAED of $\mathrm{Fe}_{2} \mathrm{Ni} \mathrm{MOF}$, the interplanar distances of (101) and (002) are $0.35 \mathrm{~nm}$ and $0.96 \mathrm{~nm},{ }^{32,33}$ which matched with the XRD results.

The XPS survey spectra for $\mathrm{Fe}_{2} \mathrm{Ni}$ MOF/NF revealed the existence of the four main constituent elements of the samples, including Fe, Ni, C, O (Fig. S4a†). The peak positions of Fe 2p and $\mathrm{Ni} 2 \mathrm{p}$ elements were corrected by $\mathrm{C} 1 \mathrm{~s}$ spectra (Fig. S4b $\dagger$ ). In the high-resolution $\mathrm{Fe} 2 \mathrm{p}$ spectra, the two main peaks of $\mathrm{Fe}_{2} \mathrm{Ni}$ $\mathrm{MOF} / \mathrm{NF}$ related to the Fe $2 \mathrm{p}_{3 / 2}$ and $\mathrm{Fe} 2 \mathrm{p}_{1 / 2}$ electron configurations were located at 714 and $725.5 \mathrm{eV}$ (Fig. 3a), suggesting the +3 oxidation state of $\mathrm{Fe}^{34}$ The spectra of $\mathrm{Ni} 2 \mathrm{p}$ could be deconvoluted to exhibit binding energy peaks at around $856.3 \mathrm{eV}$ and $874.1 \mathrm{eV}$ for $\mathrm{Ni} 2 \mathrm{p}_{3 / 2}$ and $\mathrm{Ni} 2 \mathrm{p}_{1 / 2}$, respectively (Fig. 3b), confirming the +2 oxidation state of $\mathrm{Ni}$ in $\mathrm{Fe}_{2} \mathrm{Ni} \mathrm{MOF} /$ $\mathrm{NF}^{35}$ In comparison with Fe MOF/NF and Ni MOF/NF, the Fe 2p spectrum shifted to higher binding energy and Ni $2 p$ spectrum shifted to lower binding energy. It implied the partial electron transfer from $\mathrm{Fe}^{3+}$ to $\mathrm{Ni}^{2+}$ through the oxygen of the ligand..$^{36,37}$ And the $\mathrm{Ni} 2 \mathrm{p}_{3 / 2}$ and $\mathrm{Ni} 2 \mathrm{p}_{1 / 2}$ peaks in $\mathrm{Fe}_{2} \mathrm{Ni} \mathrm{MOF} / \mathrm{NF}$ were
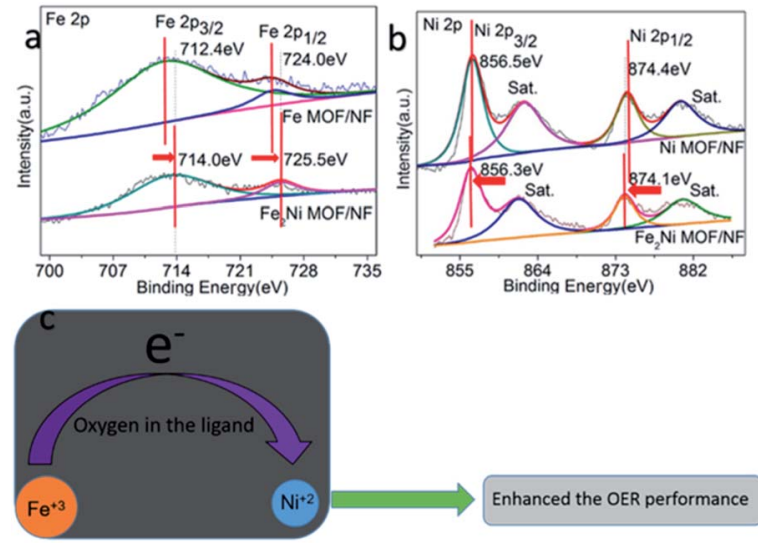

Fig. 3 High-resolution XPS spectra of (a) Fe $2 p$ and (b) Ni $2 p$ of the asprepared samples. (c) The interaction between $\mathrm{Ni}$ and Fe during the OER processes. 
located at lower binding energy, indicating an increase of $3 \mathrm{~d}$ orbital electron density of $\mathrm{Ni}^{38,39}$ It was reported that the Ni site with electron-rich structure will increase OER activity because the OER activity of the transition metal-based material was determined by the interaction of the adsorbed $\mathrm{OOH}$ species with the $3 \mathrm{~d}$ orbital of the transition metal. ${ }^{\mathbf{4 0 , 4 1}}$ From the deconvoluted XPS of $\mathrm{C}$ 1s in Fig. S4b, $\dagger$ three peaks located at 283.1, 283.6 and $283.4 \mathrm{eV}$ are assigned to adventitious hydrocarbon, $\mathrm{C}-\mathrm{O}$, and carbonate species, respectively. The O 1s XPS of the prepared samples were fitted into three peaks at 531.54, 531.99, and $531.82 \mathrm{eV}$ (Fig. S4c $\dagger$ ). Meanwhile, all the prepared samples have almost the same $\mathrm{C} 1 \mathrm{~s}$ and $\mathrm{O} 1 \mathrm{~s}$ binding energies, indicating that they are in the same chemical states. ${ }^{42}$

The OER activities of the as-synthesized samples were evaluated in $1.0 \mathrm{M} \mathrm{KOH}(\mathrm{pH}=14)$. Fig. 4a showed the LSV curves of $\mathrm{Fe}_{2} \mathrm{Ni} \mathrm{MOF} / \mathrm{NF}$, Ni MOF/NF, Fe MOF/NF, and blank NF. Due to the transfer of electrons between Fe and Ni. The OER activity of the transition metal-based material was determined by the interaction of the adsorbed $\mathrm{OOH}$ species with the $3 \mathrm{~d}$ orbital of the transition metal. $\mathrm{Fe}_{2} \mathrm{Ni} \mathrm{MOF} / \mathrm{NF}$ exhibited the highest OER activity. There was an oxidation peak in the process of the rising LSV curve. ${ }^{43}$ So we select the data of the inverse curve of CV. It only required an overpotential of $222 \mathrm{mV}$ at $10 \mathrm{~mA} \mathrm{~cm} \mathrm{~cm}^{-2}$ (Fig. S5a $\dagger$ ). The Tafel slope of the corresponding electrode could be seen from Fig. $4 \mathrm{~b}$, where $\mathrm{Fe}_{2} \mathrm{Ni} \mathrm{MOF} / \mathrm{NF}$ showed the smallest Tafel slope (42.39 $\mathrm{mV} \mathrm{dec}^{-1}$ ) since the electrons in Fe are transferred to Ni. The EIS was performed at $1.63 \mathrm{~V}(v s$. RHE) to further study the OER kinetic characteristics of the electrodes. From the Nyquist plots in Fig. 4c, benefiting from the interaction between $\mathrm{Fe}^{3+}$ and $\mathrm{Ni}^{2+}$, the charge-transfer resistance $\left(R_{\mathrm{ct}}\right)$ of $\mathrm{Fe}_{2} \mathrm{Ni} \mathrm{MOF} / \mathrm{NF}$ was much less than that of $\mathrm{Ni} \mathrm{MOF} / \mathrm{NF}$ and $\mathrm{Fe}$ MOF/NF. Fig. 5a-d expressed the MOF of $\mathrm{Fe}: \mathrm{Ni}=7: 3$ performed as the best OER activity compared to $\mathrm{Fe}: \mathrm{Ni}=3: 7$ and $\mathrm{Fe}: \mathrm{Ni}=5: 5$. Because the electrons in Fe are fully transferred to Ni when the Ratio was $7: 3$. For commercial water splitting, the electrode material should have excellent long-term stability. Here, the $\mathrm{Fe}_{2} \mathrm{Ni} \mathrm{MOF} / \mathrm{NF}$ electrode was tested with
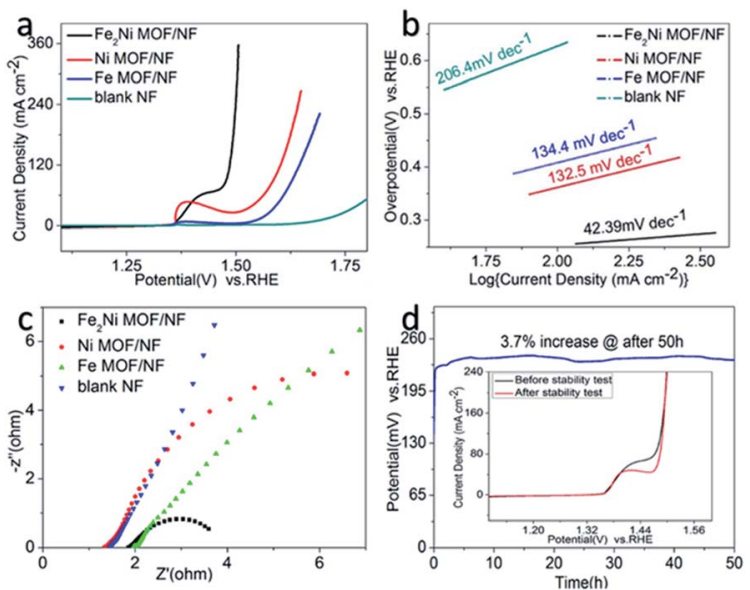

Fig. 4 (a) CV curves, (b) Tafel plots and (c) Nyquist plots of $\mathrm{Fe}_{2} \mathrm{Ni} \mathrm{MOF} /$ NF, Ni MOF/NF, Fe MOF/NF and blank NF. (d) Chronopotentiometric durability of $\mathrm{Fe}_{2} \mathrm{Ni} \mathrm{MOF/NF}$ at $10 \mathrm{~mA} \mathrm{~cm} \mathrm{~cm}^{-2}$ for $50 \mathrm{~h}$. (Insets of d) LSV curves of $\mathrm{Fe}_{2} \mathrm{Ni} \mathrm{MOF} / \mathrm{NF}$ before and after the long-term test.
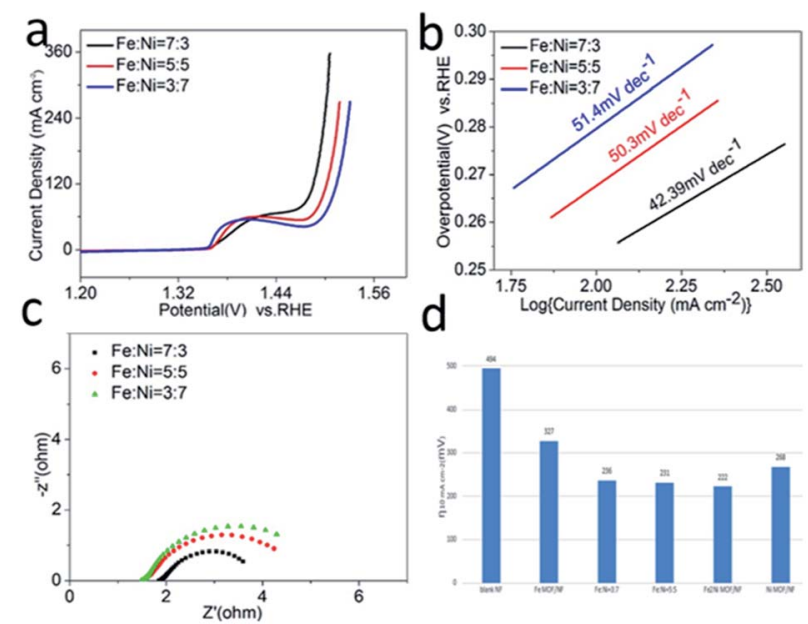

Fig. 5 (a) LSV curves, (b) Tafel plots, and (c) Nyquist plots of $\mathrm{Fe}: \mathrm{Ni}=$ $7: 3, \mathrm{Fe}: \mathrm{Ni}=5: 5$ and $\mathrm{Fe}: \mathrm{Ni}=3: 7$. (d) Overpotentials of Fe MOF, $\mathrm{Ni}$ MOF and FeNi MOF at $10 \mathrm{~mA} \mathrm{~cm}^{-2}$ vs. RHE.

chronopotentiometry $(V-t)$ measurements, the achieved current densities increased by only $3.7 \%$ compared with the initial after a $50 \mathrm{~h}$ continuous operation (Fig. $4 \mathrm{~d}$ ). In addition, there was no obvious attenuation between the LSV curves obtained before and after the stability test, indicating that the $\mathrm{Fe}_{2} \mathrm{Ni} \mathrm{MOF} / \mathrm{NF}$ not only had good OER activity but also provided excellent electrochemical stability (insets of Fig. 4d). The activity comparison with recently reported MOF catalysts was conducted in Table S3.†

\section{Conclusions}

In conclusion, an efficient and durable $\mathrm{Fe}_{2} \mathrm{Ni} \mathrm{MOF} / \mathrm{NF}$ was prepared by a one-pot method. Compared to the Fe MOF/NF and $\mathrm{Ni} \mathrm{MOF} / \mathrm{NF}$, the $\mathrm{Fe}_{2} \mathrm{Ni} \mathrm{MOF} / \mathrm{NF}$ exhibited more effective OER activity owing to the interaction between $\mathrm{Fe}^{3+}$ and $\mathrm{Ni}^{2+}$. The $\mathrm{Ni}$ site with an electron-rich structure will increase OER activity because the OER activity of the transition metal-based material was determined by the interaction of the adsorbed $\mathrm{OOH}$ species with the $3 \mathrm{~d}$ orbital of the transition metal. As a result, $\mathrm{Fe}_{2} \mathrm{Ni}$ MOF/NF had a low OER overpotential of $222 \mathrm{mV}$ at $10 \mathrm{~mA} \mathrm{~cm} \mathrm{~cm}^{-2}$ and a small Tafel slope of $42.39 \mathrm{mV} \mathrm{dec}^{-1}$. In addition, its longterm stability provided the possibility for commercial water splitting applications.

\section{Conflicts of interest}

There are no conflicts to declare.

\section{Acknowledgements}

This work was supported by NSF of China (No. 21972065, 21773114), NSF of Jiangsu Province (No. BK20171246), the Fundamental Research Funds for the Central University (020414380135) and Nanjing University Innovation and Creative Program for PhD candidate (CXCY18-15). 


\section{References}

1 S. D. Tilley, Adv. Energy Mater., 2019, 9, 1802877.

2 Z. W. Seh, J. Kibsgaard, C. F. Dickens, I. Chorkendorff, J. K. Norskov and T. F. Jaramillo, Science, 2017, 355, eaad4998.

3 H. Jin, C. Guo, X. Liu, J. Liu, A. Vasileff, Y. Jiao, Y. Zheng and S.-Z. Qiao, Chem. Rev., 2018, 118, 6337.

4 X. F. Lu, L. Yu and X. W. Lou, Sci. Adv., 2019, 5, eaav6009.

5 Y. Lee, J. Suntivich, K. J. May, E. E. Perry and S.-H. Yang, J. Phys. Chem. Lett., 2012, 3, 399.

6 L. C. Seitz, C. F. Dickens, K. Nishio, Y. Hikita, J. Montoya, A. Doyle, C. Kirk, A. Vojvodic, H. Y. Hwang, J. K. Norskov and T. F. Jaramillo, Science, 2016, 353, 1011.

7 X. Wang, L. Yu, B. Y. Guan, S. Song and X. W. Lou, Adv. Mater., 2018, 30, 1801211.

8 A. Aijaz, J. Masa, C. Reosler, W. Xia, P. Weide, A. J. Botz, R. A. Fischer, W. Schuhmann and M. Muhler, Angew. Chem., Int. Ed., 2016, 554087-554091.

9 X. Wang, L. Yu, B. Y. Guan, S. Song and X. W. Lou, Adv. Mater., 2018, 30, 1801211.

10 X. R. Li, J. L. Wei, Q. Li, S. S. Zheng, Y. X. Xu, P. Du, C. Y. Chen, J. Y. Zhao, H. G. Xue, Q. Xu and H. Pang, Adv. Funct. Mater., 2018, 28, 1800886.

11 Q. Liu, L. Xie, F. Qu, Z. Liu, G. Du, A. M. Asiri and X. Sun, Inorg. Chem. Front., 2017, 41120-41124.

12 F. Du, L. Shi, Y. T. Zhang, T. Li, J. L. Wang, G. H. Wen, A. Alsaedif, T. Hayatf, Y. Zhou and Z. G. Zou, Appl. Catal., B, 2019, 253, 246-252.

13 J. M. V. Nsanzimana, Y. C. Peng, Y. Y. Xu, L. Thia, C. Wang, B. Y. Xia and X. Wang, Adv. Energy Mater., 2018, 8, 1701475.

14 F. Du, Y. T. Zhang, H. C. He, T. Li, G. H. Wen, Y. Zhou and Z. G. Zou, J. Power Sources, 2019, 431, 182-188.

15 H. Furukawa, K. E. Cordova, M. O'Keeffe and O. M. Yaghi, Science, 2013, 341, 1230444.

16 J. Liang, Z. Liang, R. Zou and Y. Zhao, Adv. Mater., 2017, 29, 1702891.

17 M. Zhang, Q. Dai, H. Zheng, M. Chen and L. Dai, Adv. Mater., 2018, 30, 1705431.

18 F. Wu, S. Zhang, B. Xu, Z. Feng, D. Sun, X. Ma, J. Zhang, J. Feng and S. Xiong, Adv. Energy Mater., 2018, 8, 1703242.

19 X. Zhang, W. Sun, H. Du, R. Kong and F. Qu, Inorg. Chem. Front., 2018, 5, 344-347.

20 Q. Liu, L. Xie, X. Shi, G. Du, A. M. Asiri, Y. Luo and X. Sun, Inorg. Chem. Front., 2018, 5, 1570-1574.

21 T. t. Sun, L. b. Xu, D. s. Wang and Y. d. Li, Nano Res., 2019, 12, 2067-2080.

22 S. Zhao, Y. Wang, J. Dong, C.-T. He, H. Yin, P. An, K. Zhao, X. Zhang, C. Gao, L. Zhang, J. Lv, J. Wang, J. Zhang,
A. M. Khattak, N. A. Khan, Z. Wei, J. Zhang, S. Liu, H. Zhao and Z. Tang, Nat. Energy, 2016, 1, 16184.

23 G. Cai, W. Zhang, L. Jiao, S. Yu and H.-L. Jiang, Chem, 2017, 2, 791-802.

24 A. Jayakumar, R. P. Antony, R. H. Wang and J.-M. Lee, Small, 2017, 13, 1603102.

25 C. Serre, C. Mellot-Draznieks, S. Surblé, N. Audebrand, Y. Filinchuk and G. Férey, Science, 2007, 315, 1828.

26 S. Zhao, Y. Wang, J. Dong, C. T. He, H. Yin, P. An, K. Zhao, X. Zhang, C. Gao and L. Zhang, Nat. Energy, 2016, 116184.

27 J. Yang, C. Zheng, P. Xiong, Y. Li and M. Wei, J. Mater. Chem. A, 2014, 2, 19005-19010.

28 G.-T. Vuong, M.-H. Pham and T.-O. Do, CrystEngComm, 2013, 15, 9694.

29 V. H. Nguyen, T. D. Nguyen, L. G. Bach, T. Hoang, Q. T. P. Bui, L. D. Tran, C. V. Nguyen, D.-V. N. Vo and S. T. Do, Catalysts, 2018, 8, 487.

30 C. Serre, C. Mellot-Draznieks, S. Surblé, N. Audebrand, Y. Filinchuk and G. Férey, Science, 2007, 315, 1828.

31 L. Zhang, Y. Ding, R. Li, C. Ye, G. Zhao and Y. Wang, J. Mater. Chem. B, 2017, 5, 5549-5555.

32 R. R. Yuan, C. L. Yue, J. L. Qiu, F. Q. Liu and A. M. Li, Appl. Catal., B, 2019, 251, 229-239.

33 D. Kim, G. Lee, S. Oh and M. Oh, Chem. Commun., 2019, 55, 43.

34 D. Senthil Raja, X.-F. Chuah and S.-Y. Lu, Adv. Energy Mater., 2018, 8, 1801065.

35 H. Wu, X. Lu, G. Zheng and G. W. Ho, Adv. Energy Mater., 2018, 8, 1702704.

36 G. Hai, X. Jia, K. Zhang, X. Liu, Z. Wu and G. Wang, Nano Energy, 2018, 44, 345.

37 M. S. Burke, M. G. Kast, L. Trotochaud, A. M. Smith and S. W. Boettcher, J. Am. Chem. Soc., 2015, 137, 3638-3648.

38 M. Gorlin, P. Chernev, J. F. De Araujo, T. Reier, S. Dresp, B. Paul, R. Krahnert, H. Dau and P. Strasser, J. Am. Chem. Soc., 2016, 138, 5603-5614.

39 N. Li, D. K. Bediako, R. G. Hadt, D. Hayes, T. J. Kempa, F. von Cube, D. C. Bell, L. X. Chen and D. G. Nocera, Proc. Natl. Acad. Sci. U. S. A., 2017, 114, 1486-1491.

40 J. L. Xing, K. L. Guo, Z. H. Zou, M. M. Cai, J. Du and C. L. Xu, Chem. Commun., 2018, 54, 7046.

41 M. Bajdich, M. García-Mota, A. Vojvodic, J. K. Nørskov and A. T. Bell, J. Am. Chem. Soc., 2013, 135, 13521-13530.

42 F. q. Zheng, D. Xiang, P. Li, Z. w. Zhang, C. Du, Z. h. Zhuang, X. k. Li and W. Chen, ACS Sustainable Chem. Eng., 2019, 7, 9743-9749.

43 J. J. Duan, S. Chen and C. Zhao, Nat. Commun., 2017, 8, 15341. 